Open Access

\title{
Predictors of nutritional status of Ethiopian adolescent girls: a community based cross sectional study
}

Molla Mesele Wassie ${ }^{1 *}$, Azeb Atnafu Gete ${ }^{1}$, Melkie Edris Yesuf ${ }^{1}$, Getu Degu Alene ${ }^{2}$, Adamu Belay ${ }^{3}$ and Tibebu Moges ${ }^{3}$

\begin{abstract}
Background: Malnutrition is a major health issue affecting children, women and adolescents globally and developing countries in particular. Adolescence is a time of enormous physiological, cognitive, and psychosocial change but it remain a neglected, difficult-to-measure and hard-to-reach population. The critical role of adolescent nutrition in the intergenerational cycle of Growth failure has not been well addressed in Ethiopia. Hence, this study assesses level of low BMI-for- age and height-for- age and their associated factors among adolescent girls in northwest Ethiopia.
\end{abstract}

Methods: Community based cross-sectional quantitative study was employed. A total of 1281 adolescent girls were included in the study. Multistage cluster sampling method was used. Pretested questionnaire were used to collect the data. The collected data were entered in to Epi Info version 3.5.3 and exported to SPSS version 20.0 software packages for further statistical analysis. The data were analyzed using bivariate and multivariate logistic regression. The degree of association between dependent and independent variables were assessed using odds ratio with $95 \%$ confidence interval and variables with $p$-value $\leq 0.05$ were considered significant.

Result: The prevalence of girls with BMI-for-age Z-score $<-2$ were $13.6 \%$ and height-for-age Z-score $<-2$ were $31.5 \%$. Being in the age group 10-14 years ( $A O R=5.83,95 \% \mathrm{Cl}: 3.26,10.44$ ), being in the age group 15-17 years ( $\mathrm{AOR}=2.06$, $95 \% \mathrm{Cl}: 1.09,3.89$ ), with poor dietary diversity score ( $\mathrm{AOR}=2.48,95 \% \mathrm{Cl}: 1.60,3.84)$, utilizing community based nutrition service ( $A O R=0.67,95 \% \mathrm{Cl}: 0.47,0.95)$ were factors significantly associated with thinness in adolescent girls. Being on the age group 10-14 years ( $\mathrm{AOR}=6.07,95 \% \mathrm{Cl}: 4.00,9.22)$, being on the age group 15-17(AOR $=1.39,95 \% \mathrm{Cl}: 1.93$, 2.09), had nutrition and health information( $A O R=1.94,95 \% \mathrm{Cl}: 1.46,2.57$ ), living in food secured households (AOR:0.65, $95 \%$ Cl: $0.50,0.84$ ) were factors affecting low height-for-age in study subjects.

Conclusion: Finding of this study indicated that prevalence of adolescents with low BMI-for-age and low height-for-age Z-score $<-2$ were high. Age, dietary diversity score and community based nutrition service utilization were factors affecting low BMl-for-Age in adolescent girls. Age, food insecurity and Nutrition and health information were factors affecting low height-for- age in adolescent girls. Improving community based nutrition service utilization, food security specially in young adolescents is highly recommended.

Keywords: Adolescent girls, Prevalence, BMl-for-age, Height-for-age, Northwest Ethiopia

\footnotetext{
* Correspondence: molmesele@gmail.com

'Departement of human Nutrition, Institute of public health, University of Gondar

Full list of author information is available at the end of the article
}

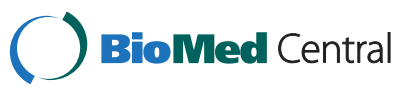

(c) 2015 Wassie et al. Open Access This article is distributed under the terms of the Creative Commons Attribution 4.0 International License (http://creativecommons.org/licenses/by/4.0/), which permits unrestricted use, distribution, and reproduction in any medium, provided you give appropriate credit to the original author(s) and the source, provide a link to the Creative Commons license, and indicate if changes were made. The Creative Commons Public Domain Dedication waiver (http://creativecommons.org/publicdomain/zero/1.0/) applies to the data made available in this article, unless otherwise stated. 


\section{Background}

According to WHO Adolescents ranged from 10-19 years and they account about $18 \%$ of the global population. They are under physiological, cognitive, and psychosocial changes but remain neglected from many health and nutrition services $[1,2]$.

The burden of energy, protein and micronutrient deficiencies is high in adolescents of developing courtiers. The subsequent social, economic, health, and development impact of under nutrition in adolescents is expected to be high in this countries [2, 3].

Malnutrition is one of the major public health issue affecting many women in Ethiopia. Twenty seven percent of women had chronic energy deficiency (BMI < 18.5), $17 \%$ of women were anemic, and $6 \%$ of rural women were experiencing night-blindness in their most recent pregnancy [3]. Undernutrition throughout the human life cycle usually starts in uterus and spans generation [4]. Malnutrition that occurs during childhood, adolescence, and pregnancy has an additive negative impact on the birth outcome of the newborn and it will have intergenerational effect. Malnourished adolescents tend to be ultimately malnourished adults and give birth to small babies [3, 5-7]. Moreover Infants with low birth weight are more vulnerable to adult-onset chronic diseases than children born at normal weight [7].

Malnutrition in adolescents may be genetically inherited, however, the vast majority of cases are linked with food insecurity, poor care and poor socioeconomic status [3]. Prematurity, short maternal stature, infections, cigarette smoking, alcohol and drug use, very young maternal age, indoor air pollution, domestic violence, closely spaced pregnancies, hypertension, stress, and malaria are all important predictors for the intergenerational effect of undernutrition [8].

The adolescent growth spurt offers a chance to compensate for earlier growth failure, although such potential is very limited [3]. Adolescence is a pivotal stage of the life cycle, and in turn, provides a unique opportunity to foster a healthy transition from childhood to adulthood and halting generational effect of malnutrition [5].

Large-scale community-based health and nutrition interventions showed promising results in improving nutritional status of adolescents in different countries [9]. In Ethiopia there are community based interventions mainly to prevent malnutrition in women and children, however there is limited effort to address malnutrition in adolescents. The current study aimed to assess the prevalence and associated factors of undernutrition in adolescent girls in Amhara region, Ethiopia. The study will be a base line for other future studies and will guide policy makers to design proper nutrition interventions for adolescents.

\section{Methods}

Study design and period

Quantitative cross sectional study was employed in December 2013.

\section{Study area}

The study was conducted at Amhara National Regional State which is located in the northwestern part of Ethiopia between $9^{\circ} 20^{\prime}$ and $14^{\circ} 20^{\prime}$ North latitude and $36^{\circ} 20^{\prime}$ and $40^{\circ} 20^{\prime}$ East longitude. Its land area is about 170,000 square kilometers [10]. The region is divided into 11 zones and 140 Weredas. There are about 3429 Kebeles (the smallest administrative units) in the region. During the study period, the community based nutrition(CBN) program was implemented in 10 Zones and 47 Woredas in Amhara region. The study was conducted in 5 major CBN implementing woredas namely Wogera, Ebnat, Wadla, Chilga and Dembecha [11].

\section{Source and study population}

All adolescent girls in all CBN sites in Amhara Region were the sources population. All adolescent girls in selected $\mathrm{CBN}$ sites in Amhara region were the study population. Those adolescent girls who were seriously ill at time of data collection were excluded in this study.

\section{Sample size}

The sample size of the Study was calculated using single population proportion formula by considering the following assumptions: Proportion of adolescents with stunting as $50 \%$, margin of error as $4 \%$, confidence level at $95 \%$, non response rate of $10 \%$ and design effect of 2 . The final sample size for this study was 1320 .

\section{Sampling procedure}

Multistage cluster sampling was employed to select adolescent girls. There were 11 zones in the region and we have selected 4 zones by simple random sampling, then we have selected 5 woredas where CBN service implemented in 4 different phases. We have selected 15 kebeles by simple random sampling technique, three kebele in each woreda. All adolescents from selected kebeles have been incorporated in the study.

\section{Variables of the study}

Stunting and thinness in adolescent girls were considered as dependent variables in this study. Adolescent girls with height-for-age Z-score $<-2$ from the median value of WHO's 2006 reference data were considered as stunted and those with BMI-for-age Z-score $<-2$ were considered as thin. Those adolescent girls with heightfor-age or BMI-for-age Z-score $<-3$ from the median value of 2006 WHO's reference data were considered as severely stunted or severely thin respectively [12]. Socio 
demographic variables, economic status, nutrition and health related characteristics were considered as independent variables.

\section{Data collection instruments and procedure}

A cross-sectional quantitative study design was employed. Structured questionnaire was used for data collection. The questionnaire was prepared in English first and then translated to Amharic and back to English by language experts to check for consistency. Twenty Nurse data collectors and 7 health officer supervisors were trained for data collection and supervision.

Weight of adolescent girls was measured using beam balance with light closing, and was measured to the nearest $0.1 \mathrm{~kg}$, and height of adolescent girls was measured to the nearest $0.1 \mathrm{~cm}$ on standing position without shoes. Checking accuracy of the scale and frequent calibrating of the scale was done.

The categories for dietary diversity were determined by first asking if the adolescent girl had eaten a particular type of food in the previous $24 \mathrm{~h}$ prior to date of data collection. These were then combined in to different food groups. Dietary diversity score(DDS) of adolescents was assessed and scored as "poor" for 0-3 food group, as "medium" for 4-5 food group and as "high" for greater than 6 food group.

Food security was assessed using 6-item module and the sum of affirmative responses to the six questions in the module was taken. The food security status of households with raw score $0-1$ was described as food secure and the two categories "low food security" and "very low food security" in combination were referred to as food insecure [13].

\section{Data quality control}

Data quality was controlled via conducting a pre-test on $5 \%$ of the samples and through supervision during data collection. The completeness of the questionnaire was also checked before data entry. Anthropometric measurements of subjects were done by trained data collectors using standard procedures.

\section{Data processing and analysis}

First code was given to the completed questionnaire and then data were entered and analyzed using SPSS version 20 statistical package. Data cleaning was performed to check for accuracy, consistencies and missed values. Any error identified has been corrected. Frequencies, proportion and summary statistics was used to describe the study population in relation to relevant variables. Anthropometric measurements were converted to height-forage $\mathrm{z}$-scores and BMI-for-age $\mathrm{z}$-scores using WHO Anthroplus software [14]. The levels of undernutrition (thinness and stunting) were regressed against the demographic, socio-economic, health and nutrition related factors. Binary logistic regression model was fitted to identify factors associated with thinness and stunting. The two outcome variables were coded as " 1 " for having thinness and stunting where as " 0 " for not having thinness and stunting. Bivariate analysis was performed and variables with $\mathrm{p}$-value $<0.2$ in the bivariate analysis were exported to multivariate logistic regression analysis in order to screen strong predictors of undernutrition. Significance was obtained at $95 \% \mathrm{CI}$ and $\mathrm{p}<0.05$.

\section{Ethical considerations}

Ethical approval has been obtained from the University of Gondar and permission letter was obtained from Amhara Regional Health Bureau and from zonal and woreda health offices. The questions from the questionnaire has proved not to affect the moral and personality of study subjects. Informed consent was obtained from each study subject after explanation of why they take part in research. They were also informed participation is volunteer based. Confidentiality has been ensured from all the data collectors, supervisors and investigators side using code numbers than names and keeping questionnaires locked.

\section{Result}

\section{Socio demographic and economic characteristics of} study subjects

A total of 1281 adolescent girls aged 10-19 years included in the final analysis among 1320 which make a response rate $97.2 \%$. Among this $499(39 \%)$ were early adolescents, $425(33 \%)$ were middle adolescents. while $357(27 \%)$ of them were late adolescents. Majority of adolescents $(83.8 \%)$ were single in marital status. Around $65 \%$ of them attended primary education and 1013(79.1\%) of them were students (Table 1 ).

\section{Nutrition and health related characteristics of adolescent girls}

Around $20 \%$ of all adolescents were consuming less than three meals per day. The mean Dietary Diversity Score(DDS) was 5.6 (SD 2.04). Among all study subjects, 664.53 \%) were practiced bellow the mean score of dietary diversity. About $33 \%$ of adolescent girls had consumed 3 or less food groups (poor dietary diversity) in the previous day, $45 \%$ had consumed 4 to 5 different food groups and $21.8 \%$ consumed 6 or more food groups. Food insecurity status was determined at household level. The research revealed that 556(44.4\%) of adolescents lived in food insecure households. Adolescents were asked to list any sickness a month prior to the survey and 241(19.2 \%) of adolescents reported sickness. Based on current physiologic state of adolescents, 27 were pregnant, 58 were lactating and the rest $91.6 \%$ were non- pregnant and nonlactating (Table 2). 
Table 1 Socio demographic characteristics of adolescent girls, Amhara region, Northwest Ethiopia, December, $2013(N=1281)$

\begin{tabular}{|c|c|c|}
\hline Variables & Frequency & Percent (\%) \\
\hline \multicolumn{3}{|l|}{ Age } \\
\hline 10 to 14 & 499 & 39.0 \\
\hline 15 to 17 & 425 & 33.2 \\
\hline 18 to 19 & 357 & 27.9 \\
\hline \multicolumn{3}{|l|}{ Woreda } \\
\hline Dabat & 256 & 20.0 \\
\hline Aykel & 256 & 20.0 \\
\hline Ebnat & 258 & 20.1 \\
\hline Wadila & 253 & 19.8 \\
\hline Dembecha & 258 & 20.1 \\
\hline \multicolumn{3}{|l|}{ Marital status } \\
\hline Single & 1073 & 83.8 \\
\hline Married & 193 & 15.1 \\
\hline Divorced & 12 & 0.9 \\
\hline Separated & 3 & 0.2 \\
\hline Newlywed & 126 & 9.8 \\
\hline \multicolumn{3}{|l|}{ Religion } \\
\hline Orthodox Christian & 1261 & 98.4 \\
\hline Muslim & 20 & 1.6 \\
\hline \multicolumn{3}{|l|}{ Ethnic group } \\
\hline Amhara & 1134 & 88.5 \\
\hline Other ${ }^{a}$ & 147 & 11.5 \\
\hline \multicolumn{3}{|l|}{ Educational status } \\
\hline Can't read/write & 71 & 5.5 \\
\hline Can read/write & 32 & 2.5 \\
\hline Primary (1 to 8 ) & 831 & 64.9 \\
\hline Secondary (9 to 12) & 315 & 24.6 \\
\hline College/university & 32 & 2.5 \\
\hline \multicolumn{3}{|l|}{ Occupation } \\
\hline Housewife & 145 & 11.3 \\
\hline Farmer & 27 & 2.1 \\
\hline Daily laborer & 6 & 0.5 \\
\hline Private/government employee & 2 & 0.2 \\
\hline Student & 1013 & 79.1 \\
\hline Jobless (unemployed) & 67 & 5.2 \\
\hline Other $^{b}$ & 21 & 1.6 \\
\hline \multicolumn{3}{|l|}{ Family size } \\
\hline$<$ or equal to 5 & 587 & 45.8 \\
\hline Greater than 5 & 694 & 54.2 \\
\hline \multicolumn{3}{|l|}{ Staple cereal } \\
\hline Teff & 484 & 37.8 \\
\hline Wheat & 398 & 31.1 \\
\hline
\end{tabular}

Table 1 Socio demographic characteristics of adolescent girls, Amhara region, Northwest Ethiopia, December, $2013(N=1281)$ (Continued)

\begin{tabular}{lll}
\hline Maize & 184 & 14.4 \\
Sorghum & 123 & 9.6 \\
Others $^{c}$ & 82 & 7.1 \\
\hline
\end{tabular}

${ }^{\mathrm{a}}$ Tigrie, oromo
${ }^{\mathrm{b}}$ Merchant, house made, shepherd (cow keeper)

'Barely, millet

\section{Prevalence and associated factors of malnutrition in} adolescent girls Prevalence of malnutrition in adolescent girls

Overall the prevalence of girls with a low body mass index-for-age $\mathrm{Z}$ score less than $<-2 \mathrm{SD}$ were $13.6 \%$ while $4 \%$ were with less than -3 SD. The overall prevalence of height-for-age Z-score less than -2 SD were $31.5 \%$ while $14.7 \%$ were with less than -3 SD.

\section{Factors affecting low BMI-for-Age in adolescent girls}

Those adolescents aged 10-14 years were 5.8 times more likely to be thin than those aged $18-19$ years $[\mathrm{AOR}=5.83$, 95 \% CI: 3.26, 10.44] where as those aged 15-17 were 2 times more likely to be thin than those aged 18-19 years [AOR $=2.06,95 \% \mathrm{CI}: 1.09,3.89]$. Adolescents with poor dietary diversity score were 2.5 times more likely to develop thinness than those having high dietary diversity score $[\mathrm{AOR}=2.48,95 \% \mathrm{CI}: 1.60,3.84]$. CBN service utilization was also other contributory factor for good nutritional status. Those who utilized $\mathrm{CBN}$ service were $33 \%$ less likely to be thin than those not utilizing CBN service $[\mathrm{AOR}=0.67,95 \% \mathrm{CI}$ : 0.47, 0.95] (Table 3).

\section{Factors affecting low height-for-age in adolescent girls}

Those adolescents aged 10-14 years were 6 times more likely to be stunted than those aged 18-19 years $[\mathrm{AOR}=6.07,95 \% \mathrm{CI}: 4.00,9.22]$ where as those aged 15-17 were 1.4 times more likely to be thin than those aged $18-19$ years [AOR $=1.40,, 95 \% \mathrm{CI}: 1.93,2.09]$. In this study adolescents who had nutrition and health information were 2 times more likely to be stunted than those who had no information $[\mathrm{AOR}=1.94,95 \% \mathrm{CI}: 1.46,2.57]$. Adolescents living in food secured households were $35 \%$ times less likely to be stunted than those living in food in secured household. (AOR:0.65, 95 \% CI: 0.50, 0.84] (Table 4).

\section{Discussion}

This cross sectional nutritional survey was conducted at five CBN implementing woredas of Amhara region. The study determined prevalence and associated factors of undernutrition in adolescent girls. Despite the fact that community based nutrition program will improve the nutritional status of women and children, prevalence of low BMI-for-age and Low height-for-age in adolescent 
Table 2 Nutrition and health related characteristics of adolescent girls in Amhara region, Northwest Ethiopia, December, 2013 $(N=1281)$

\begin{tabular}{lll}
\hline Variable & Frequency & Percent \\
\hline Physiological state & & \\
Not pregnant/lactating & 1174 & 91.6 \\
Pregnant & 27 & 2.1 \\
Lactating & 58 & 4.5 \\
Pregnant and lactating & 2 & .2 \\
Don't know & 20 & 1.6 \\
Dietary Diversity Score & & \\
Poor(0-3 food group) & 417 & 32.6 \\
Medium(4-5 food group) & 585 & 45.7 \\
High(6+ food group) & 279 & 21.8 \\
Meal frequency total & & \\
Less than 3 meal & 266 & 20.8 \\
3 plus meal & 1015 & 79.2
\end{tabular}

Meal frequency (non pregnant) $(N=1252)$

Once

Twice

Three and more times

Food security

Food insecure

Food secure

Knowledge on vitamin A rich foods

Green vegetable and other vegetable, fruits egg, 163 meat, milk

I don't know

Knowledge on iron rich foods

Teff, meat

I don't know

Availability of home garden

Yes

Disease reported in last one month $(\mathrm{N}=1252)$

Yes

Access to health and nutrition information from health extension workers

$$
\begin{aligned}
& \text { No information } \\
& \text { Growth monitoring } \\
& \text { Adolescent girls nutrition } \\
& \text { Maternal nutrition } \\
& \text { Exclusive breast feeding } \\
& \text { Complementary feeding }
\end{aligned}
$$

Table 2 Nutrition and health related characteristics of adolescent girls in Amhara region, Northwest Ethiopia, December, 2013 ( $N=1281)$ (Continued)

\begin{tabular}{lll}
\hline Family planning & 93 & 7.3 \\
Child care & 53 & 4.1 \\
Nutrition during pregnancy & 67 & 5.2 \\
Nutrition during lactation & 163 & 12.7 \\
\hline
\end{tabular}

girls were found to be high in the study setting which were $13.6 \%$ and $31.5 \%$ respectively.

The prevalence of low BMI-for-age is comparable with the national nutrition baseline survey report for the NNP of Ethiopia which was14\% [15] and lower than a study done in northern part of Ethiopia (58.3\%) [16] and Varanasi rural India (26.6\%) [17]. However, the prevalence is higher than a study in Addis Abeba Ethiopia (6.2 \%) [18]. The variation in prevalence could be explained in socioeconomic and urban-rural difference between the study subjects and settings. Low prevalence as compared to the study in northern Ethiopia may be due to the current study was conducted after the introduction of community based program in Ethiopia.

The prevalence of low Height-for-age is higher than the national base line survey which was $23 \%$ [15], northern part of Ethiopia [16] and Addis Abeba town [18]. The reason could be our survey is done in Amhara region in which adolescents may have a different feeding habit. High levels of stunting in the study setting may be due to early marriage and early pregnancy which is high in the region. The other possible reason could be the others were conducted in the age group of 13-19 in which the most vulnerable groups were not included.

In this survey, variation in development of thinness was observed across different age groups. Young adolescent girls were more likely to be thin than older adolescent girls in this study (Table 3 ). The findings of this study was in line with a study in Northern Ethiopia and Ambo town $[16,19]$. This may be due to the fact that age $10-14$ is the time of adolescent growth spurt in which there is an increased demand of essential nutrients. Hence, if the requirement for achieving the their maximum need is not fulfilled they will be prone to malnutrition.

The DDS is one of best indicators of both macronutrient and micronutrient intake. The current study revealed that adolescent girls with higher DDS were more likely to have normal BMI-for- age Z scores as compared to those having low DDS (Table 3). This is because when the DDS is high, adolescents will get adequate energy, and other important nutrients having role in growth and development.

Age of adolescent girls was also important predictor of stunting in adolescent girls in which early adolescents aged 10-14 years were more likely to be stunted as 
Table 3 Both bivariate and multivariate result of factors affecting body mass index-for-age of adolescent girls, Amhara region, Northwest Ethiopia, 2013

\begin{tabular}{|c|c|c|c|c|}
\hline \multirow[b]{2}{*}{ Variable } & \multicolumn{2}{|c|}{ 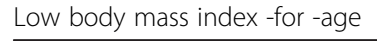 } & \multicolumn{2}{|l|}{$\mathrm{OR}(95 \% \mathrm{Cl})$} \\
\hline & Yes & No & Crude OR(95\% Cl) & Adjusted OR(95\% Cl) \\
\hline \multicolumn{5}{|l|}{ Age } \\
\hline 10 to 14 & 118 & 381 & $7.08(3.99,12.56)$ & $5.83(3.26,10.44)$ \\
\hline 15 to 17 & 38 & 381 & $2.28(1.21,4.28)$ & $2.06(1.09,3.89)$ \\
\hline 18 to 19 & 14 & 320 & 1 & 1 \\
\hline \multicolumn{5}{|l|}{ DDS } \\
\hline Low & 53 & 134 & $3.48(2.30,5.27)$ & $2.48(1.60,3.84)$ \\
\hline Medium & 57 & 420 & $1.19(0.81,1.75)$ & $0.96(0.64,1.44)$ \\
\hline High & 60 & 528 & 1 & 1 \\
\hline \multicolumn{5}{|c|}{ Community based nutrition service utilization } \\
\hline Yes & 65 & 595 & $0.51(0.36,0.71)$ & $0.67(0.47,0.95)$ \\
\hline No & 105 & 487 & 1 & 1 \\
\hline
\end{tabular}

compared with those 18-19 years old (Table 4). This finding is consistent with the baseline national nutrition survey and a study in northern Ethiopia $[15,16]$. Those early adolescents are at the greatest gain in height as compared to late adolescents. Hence, Failing to achieve their nutrient needs for this period will make early adolescents more susceptible for developing chronic malnutrition.

Adolescents living in food secure households were $35 \%$ times less likely to be stunted than those living in food insecure household (Table 4). This finding is consistent with a study in Jimma Zone, southwest Ethiopia [20]. This is because food security is one of the important determinant of chronic nutritional insult in adolescent girls.

In this study adolescents who had no nutrition and health information were 2 times more likely to be stunted than those who had information (Table 4). This is because adolescents getting nutrition information will change their dietary habit which can improve their nutritional status.

Even though the study is conducted in wider coverage it may not address cause and effect relationship between variables since it is a cross sectional study. There may be recall and social desirability bias in listing food items eaten in the past $24 \mathrm{~h}$. More over DDS did not measure quantity of food eaten by this adolescents.

\section{Conclusion}

Prevalence of adolescents with low BMI for age and Height for age $\mathrm{Z}$ score less than $<-2 \mathrm{SD}$ were high. Age, dietary diversity score and $\mathrm{CBN}$ service utilization were factors affecting low BMI for Age in adolescent girls. Age, food

Table 4 Both bivariate and multivariate result of factors affecting low height-for-age in adolescent girls, Amhara region, Northwest Ethiopia, 2013

\begin{tabular}{|c|c|c|c|c|}
\hline \multirow[b]{2}{*}{ Variable } & \multicolumn{2}{|c|}{ Low height for age } & \multicolumn{2}{|l|}{ OR } \\
\hline & Yes & No & Crude OR(95 \% Cl) & Adjusted OR(95\% Cl) \\
\hline \multicolumn{5}{|l|}{ Age } \\
\hline 10 to 14 & 262 & 237 & $6.34(4.51,8.91)$ & $6.07(4.00,9.22)$ \\
\hline 15 to 17 & 89 & 336 & $1.52(1.05,2.21)$ & $1.39(1.93,2.09)$ \\
\hline 18 to 19 & 53 & 304 & 1 & 1 \\
\hline \multicolumn{5}{|c|}{ Nutrition and health information } \\
\hline No information & 122 & 356 & $1.58(1.23,2.03)$ & $1.94(1.46,2.57)$ \\
\hline Had information & 282 & 521 & 1 & 1 \\
\hline \multicolumn{5}{|l|}{ Food insecurity } \\
\hline Yes & 153 & 467 & $0.54(0.42,0.68)$ & $0.65(0.50,0.84)$ \\
\hline No & 251 & 410 & 1 & 1 \\
\hline \multicolumn{5}{|l|}{ Home gardening } \\
\hline Yes & 241 & 544 & 1 & 1 \\
\hline No & 163 & 333 & $1.11(0.87,1.41)$ & $1.27(0.96,1.67)$ \\
\hline
\end{tabular}


insecurity and access to Nutrition and health information were factors affecting low height for age in adolescent girls. Considering adolescents as one of major target groups for $\mathrm{CBN}$ and give training to health extension workers and Women development army about nutrition services to be delivered to adolescents is recommended.

\section{Abbreviations}

AOR: Adjusted odds ratio; BMl: Body mass index; $\mathrm{CBN}$ : Community based nutrition; COR: crude odds ratio; DDS: Dietary diversity score; NNP: National Nutrition Program; SD: Standard deviation; SPSS: Statistical packages for social sciences.

\section{Competing interests}

The authors declare that they have no competing interests.

\section{Authors' contributions}

The authors' responsibilities were as follows-MM, AA, ME, GD, TM and AB: designed and supervised the study and ensured quality of the data and made a substantial contribution to the local implementation of the study. MM did the analysis and interpretation of the data. MM, the corresponding author wrote the manuscript and had the final responsibility to submit it for publication. All authors read and approved the final manuscript.

\section{Authors' information}

Not applicable.

\section{Availability of data and materials}

Not applicable.

\section{Acknowledgment}

The authors are grateful for Ethiopian Public Health Institute and University of Gondar for their support for the accomplishment of this study. The authors are also thankful for officials of Amhara National Regional State Health Bureau, Zonal and Woreda Administrative Health offices for delivering necessary information for this study. We would also like to thank supervisors and data collectors for taking their precious time to collect the data. This survey will not be true without the financial support from the Global Fund. Last but not least, we are glad to thank the adolescent girls who participated in this study and took their time to provide information.

\section{Funding}

Global Fund financialy support this study.

\section{Author details}

'Departement of human Nutrition, Institute of public health, University of Gondar. ${ }^{2}$ Departement of Epidemiology and Biostatistics, Institute of public health, University of Gondar. ${ }^{3}$ Ethiopian public health Institute, Addis Abeba, Ethiopia.

Received: 23 December 2014 Accepted: 11 September 2015

Published online: 16 September 2015

\section{References}

1. Standing Committee Nutrition. United Nations System. Adolescence: A pivotal stage in the life cycle. SCN Developments in international Nutrition. 2005.

2. Kraisid Tontisirin GS. Linking Community-based Programs and Service Delivery for Improving Maternal and Child Nutrition. Asian Dev. Rev. 1999;17:33-65.

3. Federal minstry of Health. Program Implementation Manual of National Nutrition Program,Addis Ababa, Ethiopia. 2008

4. Gillespie SR and AM. Implementation Completion Report of the Second TamilNadu Integrated Nutrition Project. 1998.

5. M B. The Role of Community Participation in Development Planning and Project Management. Washington DC: Economic Development Institute of The World Bank; 1988.

6. Bhutta ZA, Das JK, Rizvi A, Gaffey MF, Walker N, Horton S, et al. Evidencebased interventions for improvement of maternal and child nutrition: what can be done and at what cost? Lancet [Internet]. 2013;382:452-77. Available from: http://www.sciencedirect.com/science/article/pii/S0140673613609964.
7. Nutrition AC on C. Ending malnutrition by 2020: an agenda for change in the millennium. Food Nutr. Bull. 2002;3-88.

8. ACC/SCN, IFPRI. 4th Report on the World Nutrition Situation - Nutrition Throughout hte Life Cycle. IFPRI, editor. Nutrition. International Food Policy Research Institute (IFPRI); 2000.

9. Verheijden MW, Kok FJ. Public health impact of community-based nutrition and lifestyle interventions. Eur J Clin Nutr. 2005;59 Suppl 1:S66-75. discussion S76.

10. Wikipedia. Amhara geography stubs. p. https://en.wikipedia.org/wiki/ Category:Amhara_geog.

11. Annual report of CBN implementing woredas. Amhara Natl. Reg. State Heal. Bureou. 2011.

12. World Health Organization. WHO Child Growth Standards: length /heightfor-age, weight-for-age, weight-for-length, weight-forheight and body mass index-for-age. Methods and development. Geneva, Switzerland: 2006.

13. Blumberg SJ, Bialostosky K, Hamilton WL, Briefel RR. The effectiveness of a short form of the household food security scale. Am J Public Health. 1999;89:1231-4.

14. WHO Anthroplus software [Internet]. Available from: http://www.who.int/ growthref/tools/en/.

15. Nutrition base line survey report for the NNP of Ethiopia: Ethiopian health and nutrition research institute. 2009.

16. Mulugeta A, Hagos F, Stoecker B, Kruseman G, Linderhof V, Abraha Z, et al. Nutritional Status of Adolescent Girls from Rural Communities of Tigray, Northern Ethiopia. Ethiop J Heal Dev. 2009.

17. Sweta Singh, Sangeeta Kansal KA. Assessment of nutritional status of adolescent girls in ruralarea of district varanasi. Indian J Res. 2012;6:30-4.

18. Yoseph G, Solomon S, Balem Demtsu BG. Nutritional status of adolescents in selected government and private secondary schools of Addis Ababa, Ethiopia. Int J Nutr Food Sci. 2014;3:504-14.

19. Yetubie M, Haidar J, Hailu Kassa JL. Socioeconomic and Demographic Factors Affecting Body Mass Index of Adolescents Students Aged 10-19 in Ambo (a Rural Town) in Ethiopia. Int. J Biomed Sci. 2010;6:321-6.

20. Belachew T, Hadley C, Lindstrom D, Getachew Y, Duchateau LKP. Food insecurity and age at menarche among adolescent girls in Jimma Zone Southwest Ethiopia: a longitudinal study. Reprod Biol Endocrinol. 2011;9:5-6.

\section{Submit your next manuscript to BioMed Central and take full advantage of:}

- Convenient online submission

- Thorough peer review

- No space constraints or color figure charges

- Immediate publication on acceptance

- Inclusion in PubMed, CAS, Scopus and Google Scholar

- Research which is freely available for redistribution 